\title{
Developing Spatial Intelligence by Utilizing City Park Green Open Space for Educational Functions
}

\author{
S Fadjarajani ${ }^{1}$, R As'ari $^{2}$ \\ \{sitifadjarajani@unsil.ac.id ${ }^{1}$ \} \\ ${ }^{1,2}$ Lecturer of Geography Education Department, Faculty of Teacher Training and Education, \\ Siliwangi University Tasikmalaya, Indonesia
}

\begin{abstract}
City Park is open land that functions as a Green Open Space in an Urban area. The function of the existence of City Park can be an aesthetic function, a means of recreational activities, education or other activities. We explore how geography contributes to research on green open space as a function of education that leads to sustainable development. The study was conducted on the Geography Subject of the population discussing environmental problems, involving 40 students divided into 5 groups. Analysis of the study of this research was carried out on how the problem-solving techniques, and student attitudes towards the problem. In learning by utilizing City Park as a green open space, it can enhance students' spatial intelligence. Through the utilization of green open space for learning, it is built by the ability to analyze and understand the characteristics of the environment, understand the concept of environment, interconnection / interrelation of sustainability and changes in the environment.
\end{abstract}

Keywords: Spatial Intelligence, Green Open Space, Educational Function

\section{Introduction}

Provision of Green Open Space is one of the problems that often occur in urban areas that have a high population density. Because it is important for planners and landscape managers to understand how city dwellers value and interact with green open spaces [1]. Green Open Space conditions are currently very dilemma for city life which tends to develop, environmental quality is degraded.

The assessment of open space in connection with its spatial configuration has become very interesting. The latest literature focuses on the aesthetic value of land use diversity and the quality of the surrounding landscape[2]. City green open space is part of spatial planning of an urban area 
filled with plants and plants to support ecological, social, cultural, economic, and aesthetic benefits, and to function as a protected area. Aside from being a protected area, green open space also functions socially as an open public space that is for social interaction places in the community such as recreational areas, sports facilities, and play areas.

Some studies of green open spaces have long been assumed to affect the health and well-being of urban residents and improve their quality of life. The results of the study show the relationship between green environmental exposure and well-being[3]. City parks are a form of action in improving the quality of the city's environment. The function of city parks, besides being an aesthetic element of city space, also functions as an ecological element of the city. As an ecological element of the city, the city park serves as a guardian and regulator of the microclimate. In addition, city parks are public facilities arranged and formed to be used by all urban communities as social facilities.

Urban green space has an important role in improving the quality of the environment, life and sustainability of an urban area[4].The existence of city parks as green open spaces provides various benefits both at national and local levels and offers many diverse benefits. Some things include; giving many contributions to social and economic life, ecological systems and local planning, and overall, to the quality of urban life. The contribution of urban green spaces can be assessed and analyzed from several perspectives including social, economic, ecological, or planning dimensions.

As a vehicle for social interaction, open space is expected to be a means of social interaction. Activities in city parks can be used as geography learning resources related to environmental problems. Through learning with field learning techniques can provide real experiences for students and provide the ability to analyze environmental problems. So that students are able to analyze and understand environmental characteristics, understand the concept of environment, interconnection / interrelation of sustainability and environmental change.

\section{Methods}

The method used is by the survey through descriptive techniques. The research step was carried out through literature review, documentation study, data collection through surveys, data analysis. Data collection was carried out on 40 students divided into 5 groups. The student is studying the Geography Subject in the discussion of environmental issues. Analysis of the study of this research was carried out on how the problem-solving techniques, and student attitudes towards the problem.

Throughout the field activities, students are involved in active and cooperative learning. This interactive learning is guided by a field guide instrument that includes specific tasks for each learning indicator. The field learning system directs students to observe, identify, measure, collect problems from the sample, ask questions, and draw conclusions. In this case the Lecturer only acts more as a facilitator and directs the analysis of the symptoms that occur during the field learning process. However, it is important to note that the external environment is one of the most complicated and difficult to control learning environments[5]. 


\section{Result and Discussion}

\subsection{Analysis of Suitability of City Parks as Green Open Space}

Not all cities can plan the same type of park and open space because different geographies and environments require localization[6]. Landscapes can be understood as dynamic interactions between biophysical, social, policy and political processes[7]. The importance of green open space to maintain the sustainability and sustainability of the ecosystem in it. There are several benefits to the existence of green open spaces from various aspects of life. These aspects include social, economic and environmental aspects.

The ecological function of city parks as green open spaces is to guarantee the procurement of open green space as part of the air circulation system (city lungs), microclimate regulators so that the air and water circulation systems naturally can take place smoothly, like shade, oxygen producers, rainwater absorbers, absorbent pollutants in air, water and soil media, as well as windbreaks.

The social and cultural functions of city parks as green open spaces are describing expressions of local culture, are communication media of the citizens of the city, places of recreation, places, and objects of education, research, and training in studying nature.

The aesthetic function enhances comfort, beautifies the city environment both from the microscale: the home page, the residential environment, and the macro: the landscape of the city as a whole, stimulates the creativity and productivity of the city residents, forming the architectural beauty factor, creating a harmonious and balanced atmosphere.

City parks are one of the main components of green open space as well as part of urban forests that have an important role as a means of socio-cultural development such as community education, various social activities, forming image and image of the city, utility facilities and supporting facilities for community activities.

Green Open Space City parks can be used to carry out various social activities in one city or part of the city. This park can be shaped like a green open space, which is equipped with

recreational facilities, playgrounds (children/toddlers), flower gardens, special parks (for the elderly), limited sports facilities, and sports complexes and open to the public.

Table 1. Results of Student Analysis on the Function of City Parks

$\begin{array}{ll}\text { Physical } & \text { vegetation as a structural element serves to protect against the } \\ \text { function } & \text { surrounding natural physical conditions such as wind, sunlight, poor } \\ \text { scenery and odor. In this case vegetation functions as a complement, } \\ \text { unifier, reinforcement, identifier, softener, and frame }\end{array}$

social function Arrangement of vegetation in a city park or city forest that is good will provide a place of highly productive social interaction. Urban forests with a variety of vegetation contain scientific values that can become living laboratories for educational and research facilities. Functions (hygiene), for example for eye and mental therapy and the functions of recreation, sports, and as a place for other social interactions. The socio-economic function of the economy, for example for friendship between countries. Urban forests can provide additional economic returns for the welfare of the population by 
producing fruits and medicines as living stalls and living pharmacies.

\section{Ecological Function} Refreshing the air or as a "city lung", Lowers city temperatures and increases humidity, As a living space for animals, Refutation and protection of soil surface from erosion, Control and reduce air and waste pollution,

Noise suppression that is from excessive noise, unwanted and often called "invisible pollution" which causes physical and psychological effects, Preservation of germplasm and bioindicator, and Fertilize the soil.

$\begin{array}{ll}\text { Aesthetic } & \text { Parks for active recreation, namely parks in which a park user activity is built, } \\ \text { Function } & \text { so that park users actively use the facilities inside, while gaining pleasure, } \\ \text { freshness, and fitness. Parks for passive recreation, namely parks that are } \\ \text { formed so that they can be enjoyed by beauty and shade, without holding any } \\ \text { activities and activities, such as reservoirs, artificial forests, greening edges, } \\ \text { green lanes, airports, and so on. }\end{array}$

Learning activities in the field allow students to obtain methodologies, work habits, knowledge, and equipment operating experience, in conditions as close as possible to their professional activities in the future[8]. Openness was identified as one of the motivating reasons for social media space that was adjusted for learning, called Social Learn. The concepts and implementation of designs that appear are explained here, focusing on what personalization means in this context, and about how learning analytics can be used to provide various types of recommendations that support learning[9].

Field learning carried out through the use of city parks as green open spaces have its own challenges. Some things to consider include; First, pre-field activities are activities to explain the steps to be taken and the process of information seeking (observation) and understand the guidelines for observations that have been made previously. The explanation before the activity is very important to avoid misperception of the problem to be studied.

Second, controlling during the field learning process in City Park. Activities are carried out by observing every activity carried out by each group member who observes. In-depth observation of students when interacting with the object of study in the City Park area.

Third, evaluation and study of the results of the analysis obtained during the process of activities in City Park. The shortcomings and difficulties faced by each group are reviewed and discussed comprehensively and collaborated with the results obtained from each group. Evaluation can be done with discussion techniques or sharing among peers. Sharing experiences during activities is an effective thing to do to get learning goals.

\subsection{Developing Spatial Intelligence by Utilizing City Park Green Open Space}

Spatial thinking, which is taught and practiced in many social sciences, is a skill that is often overlooked in social work curricula. Spatial thinking enhances perceptions, logic, and organized learning goals and therefore improves social work practices[10]. Developing skills in spatial 
thinking offers social workers additional tools for problem-solving at all levels of practice. Finally, spatial thinking increases awareness of problem-solving techniques in relation to environmental resources, a key aspect of system theory. Fortunately, spatial thinking can be easily integrated into various social work classes that help students master skills and understand the importance of them.

Basic geography skills (Geography literacy) include an understanding of the location, potential and development of the region, events that occur in the present, skills in reading maps and using computers as geographic information. Factors that cause difficulties in teaching geography and the low level of geographical literacy between geography are part of social studies, teachers have little or no training in the development of geographic knowledge, geography learning is not integrated (human and physical) in schools, and geography is not a core lesson.

Geography is a bridge of natural and social sciences. Geography studies natural forms and how natural forms affect humans, shapes the structure of human life, whereas humans always experience processes and processes that affect nature. People modify the spaces they live in, in turn are modified by them society creates space, space creates society [11]. Geographic thinking requires intellectual knowledge about space. Knowledge about space consists of the recognition and elaboration of the relations among spatial concepts, the advanced associations derived from these concepts, and the formal linking of the associations into theories and generalizations [12].

The benefits of geography literacy for personal life, the world of work and citizens, namely; in our personal lives, making well-reasoned decisions about where to live, how to commute, and what products to buy can save time and money, protect the environment, and improve personal health and welfare [13]. Through creative geography learning by utilizing the surrounding environment as a learning resource, it can improve literacy geography for students who are important for life interests, enrich lives, fully participate responsibly for local, regional, national and international events. Understand world events and be able to solve problems related to environmental, national and world issues. With space intelligence, it is expected to be able to develop spatial behavior that is just and responsible, efficient, and effective. Students can develop geographical skills in the form of understanding facts, visualizing data in the form of maps, analyzing and reading geographical data.

Literacy contains process skills for learning, applying practical knowledge, skills that have been applied automatically in life. Literacy can also be interpreted as an understanding of the text. In literacy utilizing geography, applying and utilizing knowledge through oral and written. The ability of individuals to demonstrate map reading skills, knowledge of spatial location of places, and understanding of peoples and culture association various regions [14].

Intelligence is defined as the ability to solve complex problems[15]. In each problem-solving everyone needs knowledge, interpretation, critical power, and creativity. A smart person will be able to have the ability to understand, interpret and benefit from every event.Geographical intelligence is very important for students to have, considering geography skills are skills needed to conduct investigations, fieldwork, interpretation of data from the field, use various geographic information technology, to draw conclusions and communicate their findings. 


\section{Conclusion}

Every material in geography has a different level of abstractness so the application of technology needs to be adjusted and updated. The acceleration of technological development is often not well followed. So it needs continuous guidance to improve student competency. Through Geography learning, spatial intelligence is needed to build geographic skills. With students' spatial skills: 1) understanding spatial, environmental and territorial patterns and processes related to the geosphere in the national and global context, 2) mastering basic skills in obtaining data and information, 3) displaying environmentally responsible behavior and wisely utilizing natural resources and 4) displaying state love behavior as citizens responsible for the integrity of the country.

Utilization of City parks as green Open Space can be an alternative field learning. Learning is done with a focus on group learning by developing students' thinking skills. field analysis can directly develop students' spatial literacy skills. problem solving can be done by open group discussion and finding out the problem solving for yourself. In this case, the function of the city park as an educational function can be further developed with diverse, creative and interesting learning models.

\section{Reference}

[1] C. D. Ives, A. Gordon, C. Oke, C. M. Raymond, A. Hehir, and S. A. Bekessy, "Spatial scale influences how people value and perceive green open space," J. Environ. Plan. Manag., vol. 61, no. 12, pp. 2133-2150, Oct. 2018.

[2] S. Cho, N. C. Poudyal, and R. K. Roberts, "Spatial analysis of the amenity value of green open space," Ecol. Econ., vol. 66, no. 2-3, pp. 403-416, Jun. 2008.

[3] M. Khotdee, W. Singhirunnusorn, and N. Sahachaisaeree, "Effects of Green Open Space on Social Health and Behaviour of Urban Residents : A Case Study of Communities in Bangkok," Procedia - Soc. Behav. Sci., vol. 36, no. June 2011, pp. 449-455, 2012.

[4] T. Baycan-levent and P. Nijkamp, "Planning and Management of Urban Green Spaces in Europe: Comparative Analysis Urban Green Spaces : Perspective," J. Urban Plan. Dev., vol. 135, no. 1, pp. 1-12, 2009.

[5] N. Orion, A. Hofstein, P. Tamir, and G. J. Giddings, "Development and validation of an instrument for assessing the learning environment of outdoor science activities," Sci. Educ., vol. 81, no. 2, pp. 161-171, Apr. 1997.

[6] L. Benton-Short, M. Keeley, and J. Rowland, "Green infrastructure, green space, and sustainable urbanism: geography's important role," Urban Geogr., vol. 40, no. 3, pp. 330351, Mar. 2019.

[7] F. J. G. Padt and J. Westerink, "Addressing Scale in Open Space Preservation: Learning from the Hague Region in the Netherlands," Tijdschr. voor Econ. en Soc. Geogr., vol. 103, no. 5, pp. 601-614, Dec. 2012.

[8] J. Fernandez, R. Marin, and R. Wirz, "Online Competitions: An Open Space to Improve the Learning Process," IEEE Trans. Ind. Electron., vol. 54, no. 6, pp. 3086-3093, Dec. 2007. 
[9] R. Ferguson and S. B. Shum, "Towards a Social Learning Space for Open Educational Resources," 2012, pp. 309-327.

[10] S. Steiner, M. A. Wagaman, and P. Lal, "Thinking Spatially: Teaching an Undervalued Practice Skill," J. Teach. Soc. Work, vol. 34, no. 4, pp. 427-442, Aug. 2014.

[11] D. Gregory and J. Urry, Social Relation and Spatial Structure. Newyork: St. Martin's Press, 1985.

[12] S. Metoyer and R. Bednarz, "Spatial Thinking Assists Geographic Thinking: Evidence from a Study Exploring the Effects of Geospatial Technology," J. Geog., vol. 116, no. 1, pp. 20-33, Jan. 2017.

[13] D. C. Edelson, "Geographic Literacy in U.S. by 2025," ArcNewa Mag., vol. 38, no. 1, 2009.

[14] R. A. Eve, "Geographic Literacy among college student," Youth Soc., vol. 205, no. 3, pp. 408-427, 1994.

[15] Stenberg and Pretz, Cognition and Intellegent. USA: Cambridge, 2005. 